\title{
Collaboration in the face of change: A successful graduate curriculum revision
}

\author{
Voncella McCleary-J ones, Patsy Smith, Cathrin Carithers, Melissa Craft, Lydia Forsythe, \\ Betty Kupperschmidt, Mary Ann Pascucci, Ann Shortridge, Deborah Wisnieski, \\ Francene Weatherby \\ College of Nursing, The University of Oklahoma, Oklahoma City, USA \\ Correspondence: Voncella McCleary-Jones, PhD, RN-BC, CNE. Address: The University of Oklahoma College of Nursing, \\ 1100 N. Stonewall Ave., CNB 382, Oklahoma City, OK 73117, USA. Telephone: 01-405-271-1491, ext. 49167. Email: \\ voncella-mccleary-jones@ouhsc.edu.
}

Received: January 30, 2013

DOI : $10.5430 /$ jnep.v4n1p33

Online Published: May 30, 2013

Accepted: April 16, 2013

ep.v4n1p33

\section{Abstract}

The reality of a rapidly changing healthcare arena forces nursing professionals to continually keep pace with advancements in nursing practice. Similarly, those responsible for educating future nurses must continue to keep abreast of changes in healthcare and nursing practice. Maintaining an up-to-date curriculum prepares nurses to adequately meet current and future challenges to the profession. This article outlines the processes undertaken by one comprehensive university in the United States to revise its graduate curriculum to prepare students for graduate-level nursing practice and to function as leaders within the healthcare arena.

\section{Key words}

Curriculum revision, Collaboration, Graduate nursing education

\section{I ntroduction}

"The only thing constant in life is change.” Francois de La Rochefoucauld

Recent developments within nursing and the healthcare arena serve as an impetus for changes in nursing education. The 2010 Affordable Care Act represents a substantial change in healthcare, which will result in a transformation of the health care system. The healthcare system will be transformed to provide safe, quality, patient-centered care that is accessible and affordable. Nursing education must be improved both before and after nurses receive their licenses, for this transformation to take place ${ }^{[1]}$. Entry-level nurses need the ability to transition smoothly from their academic programs to the practice environments, particularly in the community and public health settings. There is a need for seamless academic progression, to facilitate nurses achieving higher levels of education. Graduate nurses will be the future leaders in practice, administration, education, and research. Therefore, nurses educated at the graduate-level need programs that can prepare them to assume roles in primary care, acute care, long-term care, and other settings. Furthermore, all nurses should practice to the full extent of their education and training, and competencies in decision making, quality improvement, systems thinking, and team leadership must be part of every nurse's professional formation ${ }^{[1]}$. 
Beginning in October 2005, Quality and Safety Education in Nursing (QSEN), funded by the Robert Wood Johnson Foundation, began addressing the challenge of preparing future nurses with the knowledge, skills, and attitudes necessary to continuously improve the quality and safety of the healthcare systems in which they work ${ }^{[2]}$. In Phase I of the project (2005-2007), six competences were defined, including five from the Institute of Medicine (IOM) ${ }^{[3]}$ : patient centered care, teamwork and collaboration, evidence-based practice, quality improvement, informatics, and safety. Additionally, sets of knowledge, skills and attitudes for each competency were created for use in pre-licensure nursing programs. Pilot schools integrated the six competencies in their nursing programs during Phase II (2007-2009) and shared their work on the QSEN website, which was launched in April, 2007 (http://qsen.org/). The website featured teaching strategies and resources. In Phase III (2009-2012), the University of North Carolina (UNC) School of Nursing and American Association of Colleges of Nursing (AACN) worked to develop the faculty expertise necessary for nursing schools to teach the competencies; instill the competencies in textbooks, licensing, accreditation, and certification standards; and promote ongoing innovation in teaching the competencies. The UNC School of Nursing held three national QSEN Forums designed to "attract innovators and nurture faculty leaders for the improvement of quality and safety education through exposure to innovations in curricular design and teaching strategies, research related to quality and safety education, and quality improvement or safety studies" ${ }^{[2]}$. The AACN held eight regional faculty development institutes in the United States to better prepare nursing faculty to teach quality and safety content in undergraduate programs. In February 2012, the Robert Wood Johnson Foundation awarded new funding to the AACN to extend the reach of the national QSEN initiative to graduate education programs. The new project built on the work done by the AACN at the undergraduate level, and provides educational resources and training to enhance the ability of faculty in master's and doctoral nursing programs to teach quality and safety competencies ${ }^{[2,4]}$. Definitions for the QSEN competencies are found in Table $1^{[5]}$.

Table 1. Definition of QSEN Competencies

\begin{tabular}{l}
$\begin{array}{l}\text { Quality Improvement (QI): Use data to monitor the outcomes of care processes and use improvement methods to design and test } \\
\text { changes to continuously improve the quality and safety of healthcare systems. }\end{array}$ \\
\hline Safety: Minimize risk of harm to patients and providers through both system effectiveness and individual performance. \\
\hline $\begin{array}{l}\text { Teamwork and Collaboration: Function effectively within nursing and interprofessional teams, fostering open communication, } \\
\text { mutual respect, and shared decision-making to achieve quality patient care. }\end{array}$ \\
\hline $\begin{array}{l}\text { Patient-centered Care: Recognize the patient or designee as the source of control and full partner in providing compassionate and } \\
\text { coordinated care based on respect for patient's preferences, values, and needs. }\end{array}$ \\
\hline $\begin{array}{l}\text { Evidence-Based Practice (EBP): Integrate best current evidence with clinical expertise and patient/family preferences and values for } \\
\text { delivery of optimal health care. }\end{array}$ \\
\hline Informatics: Use information and technology to communicate, manage knowledge, mitigate error, and support decision making. \\
\hline
\end{tabular}

Benner and colleagues ${ }^{[6]}$ conducted field research at a variety of U.S. nursing schools, and launched a national survey of teachers and students in cooperation with the National League for Nursing, AACN, and the National Student Nurses Association. The research resulted in four key findings focused on nursing educators' ability to prepare nurses for the complexities of practice. Several recommendations were provided for nursing programs related to changes in approaches to fostering student learning, as well as a number of recommendations for specific policy changes to facilitate the transformation of nursing education. The recommendations that have most relevance to graduate curricula include: 1) promote and support of learning the skills of inquiry and research, 2) support students in becoming agents of change, 3) provide faculty with resources to stay clinically current, and 4) cooperate on accreditation - specifically, accrediting agencies should cooperate on interdisciplinary education. "Learning to practice in an interdisciplinary setting can help students work more effectively on a health care team and better integrate knowledge, skilled know-how, and ethical comportment in practice” ${ }^{[6]}$.

The AACN published a new Essentials of Master's Education in Nursing in $2011^{[7]}$. The Essentials represent core educational elements for all master's programs in nursing and provide the necessary curricular elements and framework for these programs. Regardless of the focus, specific major or intended practice setting of the graduate, the Essentials delineate the outcomes expected of all graduates of master's nursing programs. It should also be noted that the Essentials 
do not address preparation for specific roles, as they may change and emerge over time, but they do provide a set of guidelines by which the design of master's programs can support advancement to doctoral level education ${ }^{[7]}$. The AACN notes that master's education must prepare the graduate to:

- Lead change to improve quality outcomes,

- Advance a culture of excellence through lifelong learning,

- Build and lead collaborative interprofessional care teams,

- Navigate and integrate care services across the healthcare system,

- Design innovative nursing practices, and

- Translate evidence into practice ${ }^{[7]}$.

The AACN further notes that if nurses are prepared according to the Essentials, the roles of nurses and the impact on health care can facilitate improved health care outcomes ${ }^{[7]}$. The nine Essentials represent the knowledge and skills all nurses prepared in master's nursing programs will acquire, and guide preparation of graduates for practice in diverse settings within the healthcare arena (see Table 2).

Table 2. AACN (2011) Essentials of Master's Education in Nursing

Essential I: Background for Practice from Sciences and Humanities

Recognizes that the master's-prepared nurse integrates scientific findings from nursing, biopsychosocial fields, genetics, public health, quality improvement, and organizational sciences for the continual improvement of nursing care across diverse settings.

Essential II: Organizational and Systems Leadership

Recognizes that organizational and systems leadership are critical to the promotion of high quality and safe patient care. Leadership skills are needed that emphasize ethical and critical decision making, effective working relationships, and a systems-perspective.

Essential III: Quality Improvement and Safety

Recognizes that a master's-prepared nurse must be articulate in the methods, tools, performance measures, and standards related to quality, as well as prepared to apply quality principles within an organization.

Essential IV: Translating and Integrating Scholarship into Practice

Recognizes that the master's-prepared nurse applies research outcomes within the practice setting, resolves practice problems, works as a change agent, and disseminates results.

Essential V: Informatics and Healthcare Technologies

Recognizes that the master's-prepared nurse uses patient-care technologies to deliver and enhance care and uses communication technologies to integrate and coordinate care.

Essential VI: Health Policy and Advocacy

Recognizes that the master's-prepared nurse is able to intervene at the system level through the policy development process and to employ advocacy strategies to influence health and health care.

Essential VII: Interprofessional Collaboration for Improving Patient and Population Health Outcomes

Recognizes that the master's-prepared nurse, as a member and leader of interprofessional teams, communicates, collaborates, and consults with other health professionals to manage and coordinate care.

Essential VIII: Clinical Prevention and Population Health for Improving Health

Recognizes that the master's-prepared nurse applies and integrates broad,

organizational, client-centered, and culturally appropriate concepts in the planning, delivery, management, and evaluation of evidence-based clinical prevention and population care and services to individuals, families, and aggregates/identified populations.

Essential IX: Master's-Level Nursing Practice

Recognizes that nursing practice, at the master's level, is broadly defined as any form of nursing intervention that influences healthcare outcomes for individuals, populations, or systems. Master's-level nursing graduates must have an advanced level of understanding of nursing and relevant sciences as well as the ability to integrate this knowledge into practice. Nursing practice interventions include both direct and indirect care components. 
The aforementioned developments led the Graduate Faculty of The University of Oklahoma College of Nursing to embark upon a journey to revise its graduate curriculum. The graduate program offers four preparation tracks: Administration/ Management, Clinical Nurse Specialist, Nurse Educator, and Nurse Practitioner. The students enrolled in each of these tracks complete a common core of graduate-level courses that the faculty believes are foundational. The revision entailed updating the curriculum to reflect current and future practice requirements as informed by information from the IOM, QSEN Institute, AACN Essentials of Master's Education in Nursing and other publications.

\section{The curricular change process}

Initial Discussions. Curricula work began at a May faculty retreat with an impromptu discussion of massive changes in the health care system and the health care environment. The new AACN Essentials of Master's Education in Nursing ${ }^{[7]}$ document, released March 2011, was of particular focus. One faculty in particular raised the question regarding how the nine identified essential elements in the report would be incorporated into the current College of Nursing master's curriculum. It was noted that the last major curricular change had occurred more than a decade earlier. At that time, the curricular organizing framework was based on the Four Cs model: Caring, Culture, Communication and Citizenship with mastery in each area resulting in a competent nurse. Four (4) core courses were required of all master's students; these core courses were designed to develop competence in the four Cs and provided a foundation for subsequent specialty track coursework. Core Courses included Theory Development in Nursing; Research in Nursing, Health Promotion and Culture in Nursing and Policy and Ethics in Nursing. A comparison of the existing core courses to the Essentials helped faculty identify notable gaps in informatics, technology, organizational functioning, and interprofessional collaboration. An additional comparison involved the emphasis on the conduct of research versus the application of research through evidence-based practices.

The curricular discussion at the May 2011 faculty retreat was quite animated with 19 graduate faculty in attendance. Absent graduate faculty members were attending other discussion sessions. All but one of the nurse practitioner faculty, for example, were attending another work session. Faculty in attendance enthusiastically worked during the two-hour discussion brainstorming how the 9 Essentials might be translated into a framework of core courses. An early point of agreement was to keep the 4 three-credit-hour core course pattern in place to avoid changes in program requirements. By the end of the discussion, four embryonic core courses were envisioned - then came the summer. Summer stretched into fall with no action taken. The faculty member who had first initiated the curricular discussion at the May retreat retired, and it appeared that the movement toward curricular change was ended or at best indefinitely stalled.

Task Force Formation. In late fall, however, a determined faculty brought the core course revision to the Graduate Faculty meeting table. A faculty who had a special interest in curricular work quickly volunteered to lead a curricular task force and was subsequently appointed by the Associate Dean for Academic Programs to chair a Graduate Core Course Revision Task Force [Task Force]. Forming the Task Force was the next step in the curricular change process. Three options for this formation were possible: 1) Have the Associate Dean appoint Task Force members; 2) Refer the curricular change project to the already established College Curriculum Committee; or 3) Open Task Force membership to any interested faculty. The third option, the Inclusion Model, was selected by the Task Force Chair. Although there was a danger of creating a working group too large to make any real progress, the inclusion model offered the advantage of great buy-in to the curricular change; and was the model selected. The Call for Members was sent out and nine faculty attended the initial Task Force meeting, indicating professional interest in being a part of the revision process. All but one of these original members attended each meeting; the one faculty retired from the College in December. The Task Force held a series of five meetings between mid-October and early December 2011. Task Force members voluntarily divided into four subcommittees representing each of the new proposed courses. Subcommittee selection was based on individual faculty expertise and interest. Subcommittees met between regularly scheduled meetings of the Task Force to work on individual courses. By December 6, 2011, the final draft for the new Graduate Core Courses was ready to be presented to the full Graduate Faculty for approval. By the end of March 2012, the proposed course revisions were approved by three bodies 
internal to the College of Nursing structure. Three Health Sciences Center bodies approved the changes by mid-Fall 2012. At each step in the process, a group of five Task Force members composed of the Task Force Chair and lead faculty from each course development subcommittee was available to answer questions from the approval body. The process of having questions answered by faculty and staff who developed the courses facilitated advancement of the course revisions through the approval processes.

\section{Core course development}

The core courses are foundational to students in the nursing master's program in that all students are required to learn essential content. Students represent diverse interests and enter the program with backgrounds in special populations, general acute care, intensive care of critically ill patients, home and hospice care, case management, long term care, and other specialties. Students are in the core courses as part of the journey toward professional goals that may diverge into nursing education, nursing administration and management, or into a clinical focus through nurse practitioner or clinical nurse specialist training.

Course descriptions and learning activities were constructed after a thorough review of the IOM Future of Nursing report $^{[1]}$, AACN Master's Essentials ${ }^{[7]}$, and other pertinent literature ${ }^{[5,8,9]}$. The selected course content formed the core of master's level knowledge consistent with recommendations from AACN Essentials, QSEN Institute, and projections from the IOM Future of Nursing report (see Table 3). Each course subcommittee developed an outline describing the structure, general content, learning activities and assignments for the course. Teaching and learning strategies are consistent with current Essentials, practice competency recommendations, and instructional techniques.

Table 3. Relationship among Essentials, competencies, and course descriptions.

\begin{tabular}{|c|c|c|c|}
\hline Core Courses & $\begin{array}{l}\text { AACN Essentials } \\
\text { Number }\end{array}$ & $\begin{array}{l}\text { IOM Competency/ } \\
\text { QSEN }\end{array}$ & $\begin{array}{l}\text { Course Description } \\
\text { and Prerequisites }\end{array}$ \\
\hline $\begin{array}{l}\text { 1. Background for } \\
\text { Nursing Practice }\end{array}$ & I,VII \& VIII & $\begin{array}{l}\text { Patient-centered } \\
\text { care, and } \\
\text { Interprofessional } \\
\text { Collaboration }\end{array}$ & $\begin{array}{l}\text { This course provides a foundation for the master's prepared } \\
\text { nurse by integrating scientific findings from nursing, } \\
\text { bio-psychosocial fields, genetics, public health, quality } \\
\text { improvement and organizational sciences across diverse } \\
\text { settings. (Permission of Instructor) }\end{array}$ \\
\hline $\begin{array}{l}\text { 2. Organizational } \\
\text { and Systems } \\
\text { Leadership in } \\
\text { Nursing }\end{array}$ & II \& VI & $\begin{array}{l}\text { Patient-centered } \\
\text { care, and } \\
\text { Interprofessional } \\
\text { Collaboration }\end{array}$ & $\begin{array}{l}\text { This course provides foundational content of managerial } \\
\text { leadership, organizational theory and principles of economics, } \\
\text { and finance. } \\
\text { (Prerequisites: Background for Nursing Practice or } \\
\text { concurrent enrollment) }\end{array}$ \\
\hline $\begin{array}{l}\text { 3. Technology, } \\
\text { Safety, and Quality } \\
\text { Improvement in } \\
\text { Nursing }\end{array}$ & III \& V & $\begin{array}{l}\text { Patient-centered } \\
\text { care, Information } \\
\text { Management, and } \\
\text { Quality } \\
\text { Improvement }\end{array}$ & $\begin{array}{l}\text { This course will prepare students to evaluate and utilize } \\
\text { information and communication technologies to enhance } \\
\text { quality improvement methods to promote safe, timely and } \\
\text { effective patient-centered care. (Permission of Instructor) }\end{array}$ \\
\hline $\begin{array}{l}\text { 4. Evidence-Based } \\
\text { Practice (EBP) \& } \\
\text { Scholarship in } \\
\text { Nursing }\end{array}$ & IV & $\begin{array}{l}\text { Patient-centered } \\
\text { care, and EBP }\end{array}$ & $\begin{array}{l}\text { This course prepares the student to challenge current practices, } \\
\text { procedures, and policies by seeking evidence for nursing } \\
\text { practice; thereby translating current evidence and identifying } \\
\text { gaps in knowledge; students will locate current evidence, } \\
\text { critically appraise peer-reviewed studies, and synthesize the } \\
\text { evidence to formulate recommendations for practice. } \\
\text { (Prerequisites: Background for Practice in Nursing) }\end{array}$ \\
\hline
\end{tabular}


A thorough review of recommended content for each course revealed duplications and omissions that were resolved through open discussion. Key to the discussions was a return to the recommendations from the stated resources. Content deemed essential to the previous curriculum, such as theoretical framework or research proposal production, was evaluated in accordance with current resources, references, and standards. Content was distributed or removed among the core courses based on topics deemed most appropriate to support learning outcomes for student development.

The newly designed core of graduate program courses consists of units or modules reflected by course descriptions and course objectives. Central to the plan for course development was the expectation for course-specific objectives. Basic structural components were similar for each course, including strategies to support student ability to understand objectives of each core focus and demonstrate competence in creating, presenting, and applying knowledge gained in each course. Students would be expected to differentiate among background concepts to include theory and populations, show leadership in administrative and organizational systems, apply technical and quality improvement measures to enhance health care and patient safety, and practice evaluation and application of the evidence for nursing practice.

The syllabus for each core course contained a description of the relationship to other courses, topical outline, and program outcomes that are reflected in learning activities. Faculty agreed to apply basic structural components to develop each course, and to communicate those components clearly in each syllabus. These components consisted of plain language to enhance understanding of course content; instructions for course assignments and learning activities that provide clear, consistent descriptions of expectations; and essential discussion items, questions or ideas to generate responses to support on-line faculty-student and student-student interaction.

Student-student interaction was agreed to as an important focus of the online learning environment. A recent evaluation of programs and curricula revealed a desire for documentation of student-student interactions in the online environment or virtual classroom. So rather than take a general view of the interaction among students, a grading rubric for student discussion was established, increasing the amount of course credit assigned to discussion participation. Examples from each core course are presented herein to provide a snapshot of how learning and interactive discussions are stimulated among students.

\section{Core Course 1: Background for nursing practice}

The subcommittee for core course 1 consisted of two Clinical Nurse Specialists and one Nurse Practitioner. Two of the faculty had taught core courses prior to this revision with one of the committee members being integrally involved in the design and conduct of the current core courses. We did not want the students to face a barrier in a precise order to take courses; however, we felt that by its essence, core course 1 needed to be a prerequisite for all the others. Essential I, Background for Practice was felt to lend itself to an excellent first core course.

The core course 1 subcommittee carefully reviewed the Master's Essentials for components necessary for a solid foundation on which to build the rest of the core courses and the specialty courses. We also considered the specific areas contained in the essentials i.e.: biopsychosocial fields, genetics, public health, quality improvement, and organizational sciences for the continual improvement of nursing care across diverse settings. The initial outline of the course content was revised in an iterative process during committee meetings in which each course was evaluated for what was particularly relevant to that course and what might be more general and relevant to all courses. Since core course 1 is the first course and the only one that serves as a prerequisite for all the others, it was scrutinized to ensure that it remained foundational and preparatory. As is the case with the other core courses, this course is conducted completely on-line with student involvement in discussion groups. Since the course is foundational to the other three courses, three major areas are covered by small papers: health policy, cultural disparity and theory analysis. Basic concepts of knowledge acquisition are covered in the first module to provide a framework for thinking about all subsequent concepts and issues. The papers are short and focus on assisting the graduate student to begin the process of scholarly application of knowledge by synthesis and concise, professional prose. Scientific foundational knowledge such as genetics and genomics are covered in the second module and assessed with short quizzes. Although examinations are viewed as controversial by some faculty who teach 
graduate courses, students completing the Advanced Practice tracks take certification exams after graduation and gaining comfort with testing is an important rationale that supports their inclusion.

\section{Core Course 2: Organizational and systems leadership in nursing}

Couched within the context of the rationale and emphasis for curricular change, a subcommittee of faculty began to develop core course 2. Organization theory, systems theory, and complexity thinking and innovation were deemed essential content for a course designed to be foundational for all graduate students. Contingency leadership theory was employed as the workgroup was formed. A faculty colleague who possessed the knowledge-base and experience requisite for developing coursework to prepare students for leadership roles in complex systems assumed leadership for course objectives and content outline. Virtual collaboration among faculty was key to the process as faculty participated across multiple campus sites. Work group meetings were held using video conferencing, and e-mail was used extensively to gain faculty input throughout the process. College of Nursing faculty with expertise in selected content such as finance and policy were consulted for input and evaluation to assure that objectives would facilitate all graduate students to be better prepared for current and evolving practice.

Textbook selection proved to be challenging. The team thought a foundational text was important, and course content could be augmented with literature from journals pertinent to each pathway. Most texts reviewed were written specifically for the formal nurse manager or nursing administrator role in acute care settings. Input from colleagues at the Council of Graduate Educators of Administration in Nursing (CGEAN) facilitated selection of the most appropriate, scholarly text. Core course 2 emerged with a blend of methodologies to assist students in the synthesis and application of organization and systems leadership theories and concepts within the practice arena. Discussion forums, case studies, scholarly papers, and a class presentation were employed to facilitate students' comprehension of managerial leadership, organizational science and economic and financial principles of healthcare.

\section{Core Course 3: Technology, safety, and quality improvement in nursing}

This course was created in collaboration with a team of interprofessional academics interested in technology, safety and applications in practice. The intent of this course is to foster a relevant connection and understanding for students in a world of evolving technology, recognizing the need for safe and quality patient healthcare delivery environments. Course development was accomplished primarily by email and with the use of the Desire 2 Learn (D2L) learning management platform. Ideas were shared and syllabus assignments were determined by faculty with specific expertise and interest in each part of the course. All course components were shared to collaborate on the final content for the course.

It is important to bring a relevant context to each learner because technology in the healthcare environment involves nursing specialty roles, complex interprofessional communication, and interactions within a multitude of healthcare settings ${ }^{[10,11]}$. The course supports an exploration of technology within the context of evidence-based clinical practice, patient education and patient safety. Adoptions of technology are based upon fads (i.e., what is commonly done) or opinion (i.e., what is recommended by experts) rather than on research based evidence of effectiveness ${ }^{[12-15]}$. Thus, consideration was given to each discussion to develop latitude yet involve pertinent technology, safety and quality related information to make this a master's level course, evoking scholarly discussion and realistic applications. Further, the discussions and assignments bring a collaborative, interprofessional focus for each learner. The course provides an opportunity to explore how to promote positive patient outcomes ${ }^{[16]}$ within a technology, safety and quality context. The course supports AACN Essentials, specifically, Quality Improvement and Safety, Informatics and Healthcare Technologies, Interprofessional Collaboration for Improving Patient and Population Health Outcomes ${ }^{[7]}$.

The course provides an avenue of learning where students can bring in real world concerns, use tools, models and ideas which in turn can be effectively translated into their professional settings. By combining case studies and guided discussion students can put concepts into context. Course elements support the use of reflective storytelling and personal narrative, fostering professional development and identity as well as clinical expertise ${ }^{[17-20]}$. The course encourages 
reflective thinking about the critical aspects of being a nurse leader within interprofessional settings and technologicallyladen healthcare delivery environments, while keeping patients safe and improving quality outcomes.

\section{Core Course 4: Evidence-based practice and scholarship in nursing}

One critical aspect of the development of this course began when the subcommittee of faculty had to decide whether the focus was to be research proposal development, evidence-based practice (EBP) or both. The entire graduate faculty was included in this discussion since decisions about focus would affect the master's level curriculum and all undergraduate and graduate programs. It was not realistic to have the course focus on research proposal development and EBP for three credit hours. Faculty decided to form levels of progression toward and beyond the master's EBP course. Discussions resulted in an undergraduate course that teaches basic appraising and summarizing evidence, the Master's level graduate course requires a systematic review, the Doctorate of Nursing practice course requires a systematic review with metaanalysis, and last, the Doctorate of Philosophy in nursing course produces research evidence.

The EBP and Scholarship course was developed using several highly regarded books that became part of the students required readings. A bigger aspect of the course involved using specific tools and procedures to conduct a systematic review for a clinical question. Web-based instructional strategies and other electronic resources as well as hard copy texts support this on-line course. Two major assignments include appraisal of best evidence about a critical clinical question, an associated paper, and an on-line presentation demonstrating application of a change model. This course clearly reflects the essential elements of master's education and the future of nursing practice.

\section{Conclusion}

The courses described in this article were launched in January 2013. Peer evaluation of each course will occur through team review and a structured plan following initial implementation. New courses may meet challenges not contemplated during course development, and course expectations may be interpreted differently during implementation. Routine evaluation may prevent curricular diversion from course description and enhance curricular revisions. A schedule is planned for faculty teaching the core courses to routinely share and evaluate ongoing course development, problem identification, and solution-finding throughout the semester to support course innovation and refinement. Going forth, the curriculum, teaching and learning strategies, and student evaluations will be factored into revision decisions. Faculty who participated in developing the new master's level core courses will convene at the end of the semester for an overall evaluation of process to include student learning experiences, and faculty teaching experiences. These measures will inform future revisions of courses and the curriculum.

\section{Acknowledgments}

The authors wish to acknowledge the contributions of the following faculty and staff: Nancy Chu, PhD, RN, GCNS-BC; Pam Crawford, MS, MBA, RN, NEA-BC; Renee Leasure, PhD, RN, CCRN, CNS; Gary Loving, PhD, RN; Cynthia Scheideman-Miller, MHSA, Special Program Coordinator, Telemedicine; Candace Shaw, Assistant Vice Provost Academic Technology and Telemedicine; Shelly Wells, PhD, MBA, MS, APRN-CNS; and Janet Wilson, PhD, RN.

\section{Author's contributions}

All authors made substantial contribution to the curriculum revision process, development and revision of this manuscript, and have given final approval of the manuscript version to be published.

\section{References}

[1] Institute of Medicine. The Future of Nursing: Leading Change, Advancing health. Washington, DC: The National Academies Press. 2011. 
[2] Quality and Safety Education for Nurses [QSEN] Institute. Project Overview. Available from: http://qsen.org/about-qsen/project-overview/

[3] Institute of Medicine. Health professions education: A bridge to quality. Washington, DC: The National Academies Press. 2003.

[4] American Association of Colleges of Nursing. AACN Extends National Nurse Faculty Development Initiative with New Funding from the Robert Wood Johnson Foundation. 2012. Available from: http://www.aacn.nche.edu/news/articles/2012/qsen

[5] American Association of Colleges of Nursing Education Consortium. Graduate-Level QSEN Competencies: Knowledge, Skills and Attitudes. 2012. Available from: http://www.aacn.nche.edu/faculty/qsen/competencies.pdf

[6] Benner P, Sutphen M, Leonard V, \& Day L. Educating Nurses: A Call for Radical Transformation. San Francisco, CA: JosseyBass. 2010.

[7] American Association of Colleges of Nursing. The Essentials of Master's Education in Nursing. Washington, DC: Author, 2011.

[8] Cronenwett L, Sherwood G, et al. Quality and safety education for advanced nursing practice. Nursing Outlook. 2009; 57(6): 338-348. PMid:19942035 http://dx.doi.org/10.1016/j.outlook.2009.07.009

[9] Disch J. QSEN? What's QSEN? Nursing Outlook. 2012; 60(2): 58-59. PMid:22306706 http://dx.doi.org/10.1016/j.outlook.2012.01.001

[10] Hughes RG. (Ed.). Patient safety and quality: An evidence-based handbook for nurses. Rockville, MD: Agency for Healthcare Research and Quality, 2008.

[11] Sadeghi S, Barzi A, Mikhail O, \& Shabot MM. Integrating quality and strategy in health care organizations. Burlington, MA: Jones and Bartlett, 2013.

[12] Benner P, Tanner C, \& Chelsa C. Expertise in Nursing Practice. New York, NY: Springer, 1996.

[13] Lorenzi NM, Ash JE, McPhee W. \& Einbinder L. (Eds.) Transforming health care through information. (2nd ed.). New York, NY: Springer, 2005. http://dx.doi.org/10.1007/b138625

[14] Lewis D, Eysenbach G, Kukafka R, Stavri, P. \& Jimison, H. (Eds.) Consumer health informatics: Informing consumers and improving health care. New York, NY: Springer, 2005. http://dx.doi.org/10.1007/0-387-27652-1

[15] Clark R, \& Mayer R. e-Learning and the science of instruction: Proven guidelines for consumers and designers of multimedia learning. (3rd ed.). CA: Pfeiffer, 2011. http://dx.doi.org/10.1002/9781118255971

[16] Forsythe LL. CMM and healthcare: Qualitative simulation research: Developing the team's voice. In C. Crede, B. Fisher-Yoshida, \& P. Gallegos (Eds.). Making lives and making meaning: Reflective, facilitative and interpretative practice of the coordinated management of meaning. Madison, NJ: Fairleigh Dickinson University Press. 2012: 1-19. PMid:23141821

[17] Charon R, \& Montello M. Stories matter: The role of narrative in medical ethics. New York, NY: Routledge, 2002.

[18] Downing SM, \& Yudkowsky R. (Eds.) Assessment in Health Education. New York, NY: Routledge, 2009.

[19] Murphy JI. Using focused refection and articulation to promote clinical reasoning: An evidence-based teaching strategy. Nursing Education Perspectives. 2004; 25(5): 226-231. PMid:15508561

[20] Kaakinen J, \& Arwood E. Systematic review of nursing simulation literature for use of learning theory. International Journal of Nursing Education Scholarship [Internet]. 2009; 6: 1. Article 16. Available from: http://www.bepress.com/ijnes/ 